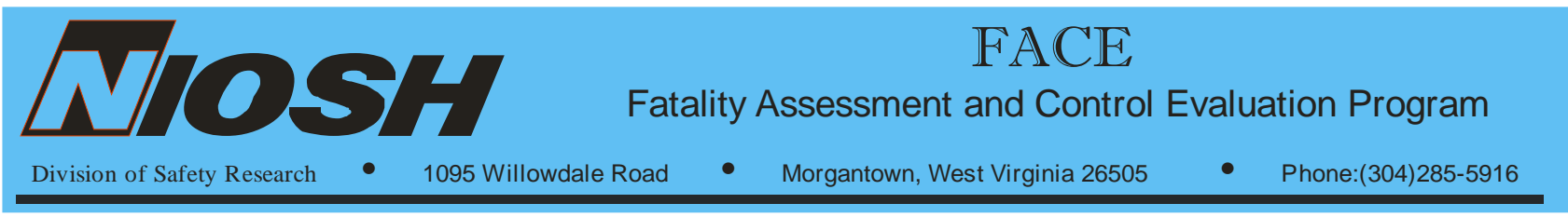

FACE Report Number 2012-01

December 11, 2014

\title{
Hispanic Lumberyard Worker Dies When Struck By a Forklift - North Carolina
}

\section{SUMMARY}

A 58-year-old Hispanic lumberyard worker died on March 30, 2012, from crushing injuries received when a forklift driven by a coworker struck him. The lumberyard laborer was walking from his work area to the employee lunchroom. At the same time, and in the same area, a coworker was operating a forklift that was loaded with lumber. The forklift operator's field of vision was limited because he was transporting the lumber "load-forward" and the load partially obscured his view. He did not see the laborer but stopped when he felt the forklift roll over something. He exited the cab and found the laborer unresponsive, lying near the left side of the forklift. The laborer was pronounced dead at the scene. The medical examiner identified head and thoracic injuries as the cause of death.

\section{CONTRIBUTING FACTORS}

Key contributing factors identified in this investigation include:

- Forklift operator's field of vision was obstructed in the direction of travel by the load of lumber he was transporting and surrounding buildings

- Equipment and pedestrian pathways were not clearly marked or their use enforced

- Laborer's ability to hear the oncoming forklift may have been hampered by noise from the dust collection unit.

RECOMMENDATIONS

NIOSH investigators concluded that, to help prevent similar occurrences, employers should:

- Develop, train on, implement, and enforce safe forklift operating procedures

- Develop, train on, implement, and enforce workplace pedestrian safety procedures

- Consider proximity warning systems when purchasing or upgrading forklifts

- Ensure that contingent workers receive all required safety training and understand safe operating procedures for each job they will be performing.

\section{Fatality Assessment and Control Evaluation (FACE) Program}

The National Institute for Occupational Safety and Health (NIOSH), an institute within the Centers for Disease Control and Prevention (CDC), is the federal agency responsible for conducting research and making recommendations for the prevention of work-related injury and illness. In 1982, NIOSH initiated the Fatality Assessment and Control Evaluation (FACE) Program. FACE examines the circumstances of targeted causes of traumatic occupational fatalities so that safety professionals, researchers, employers, trainers, and workers can learn from these incidents. The primary goal of these investigations is for NIOSH to make recommendations to prevent similar occurrences. These NIOSH investigations are intended to reduce or prevent occupational deaths and are completely separate from the rulemaking, enforcement and inspection activities of any other federal or state agency. Under the FACE program, NIOSH investigators interview persons with knowledge of the incident and review available records to develop a description of the conditions and circumstances leading to the deaths in order to provide a context for the agency's recommendations. The NIOSH summary of these conditions and circumstances in its reports is not intended as a legal statement of facts. This summary, as well as the conclusions and recommendations made by NIOSH, should not be used for the purpose of litigation or the adjudication of any claim. For further information, visit the program website at www.cdc.gov/niosh/face/ or call toll free at 1-800-CDC-INFO (1-800-232-4636). 


\section{INTRODUCTION}

On March 30, 2012, a 58-year-old Hispanic lumberyard laborer died when a forklift operated by a coworker struck him. On April 2, 2012, officials of the North Carolina Department of Labor (NCDOL), Occupational Safety and Health Division (NCDOL/OSH), notified the National Institute for Occupational Safety and Health (NIOSH), Division of Safety Research (DSR), Fatality Assessment and Control Evaluation (FACE) program of the fatality. On July 27, 2012, a Safety and Occupational Health Specialist, and a Health Scientist conducted an investigation of the fatality and reviewed circumstances of the incident with the investigating NCDOL/OSH Safety Compliance Officer. Photographs of the incident site and statements taken by the NCDOL/OSH Safety Compliance Officer from workers who were in the general area where the fatality occurred were reviewed. On July 28, 2012, the NIOSH investigators met with the laborer's employer and took photographs of the area where the incident occurred.

\section{EMPLOYER}

The lumberyard laborer was employed through a staffing agency and was working at a 100,000 square foot lumber processing facility as a contingent worker. Work at the location involved receiving green unprocessed lumber, moving it through a sorting area, and then running it through a planer followed by a kiln drying process. Once the lumber was dried, it was moved from the kiln to a storage area and prepared for shipment, mostly to furniture manufacturers. The company has been in business at this location since 1978 and employs, on average, 35 permanent and 15 contingent workers. The site encompasses 25 acres and includes 19 buildings. The facility is operated on a 7:00 A.M. to 3:30 P.M. daily shift. This was the company's first fatality.

This report will focus on three buildings, the canopy building \#7 (B7), the new stacker building \#8 (B8), and the stacker building \#9 (B9), as well as the central travel area common to all three buildings (Diagram).

\section{WRITTEN SAFETY PROGRAMS and TRAINING}

The employer had developed a written occupational safety and health program that consisted of monthly safety meetings with all employees and contractors. Job-specific safety training, including a video and hands-on exercises, was conducted upon initial hire or appointment, when job duties changed, and at a minimum every three years thereafter. Personal protective equipment, including gloves, safety glasses, and hearing protection, were provided upon initial hire and each employee was given an employee handbook. Safety rules were enforced and progressive discipline, up to and including termination were implemented. The employer's safety program addressed the issue of forklifts traveling with a clear vision of the path of travel and sounding horns when approaching intersections and pedestrian walkways. 

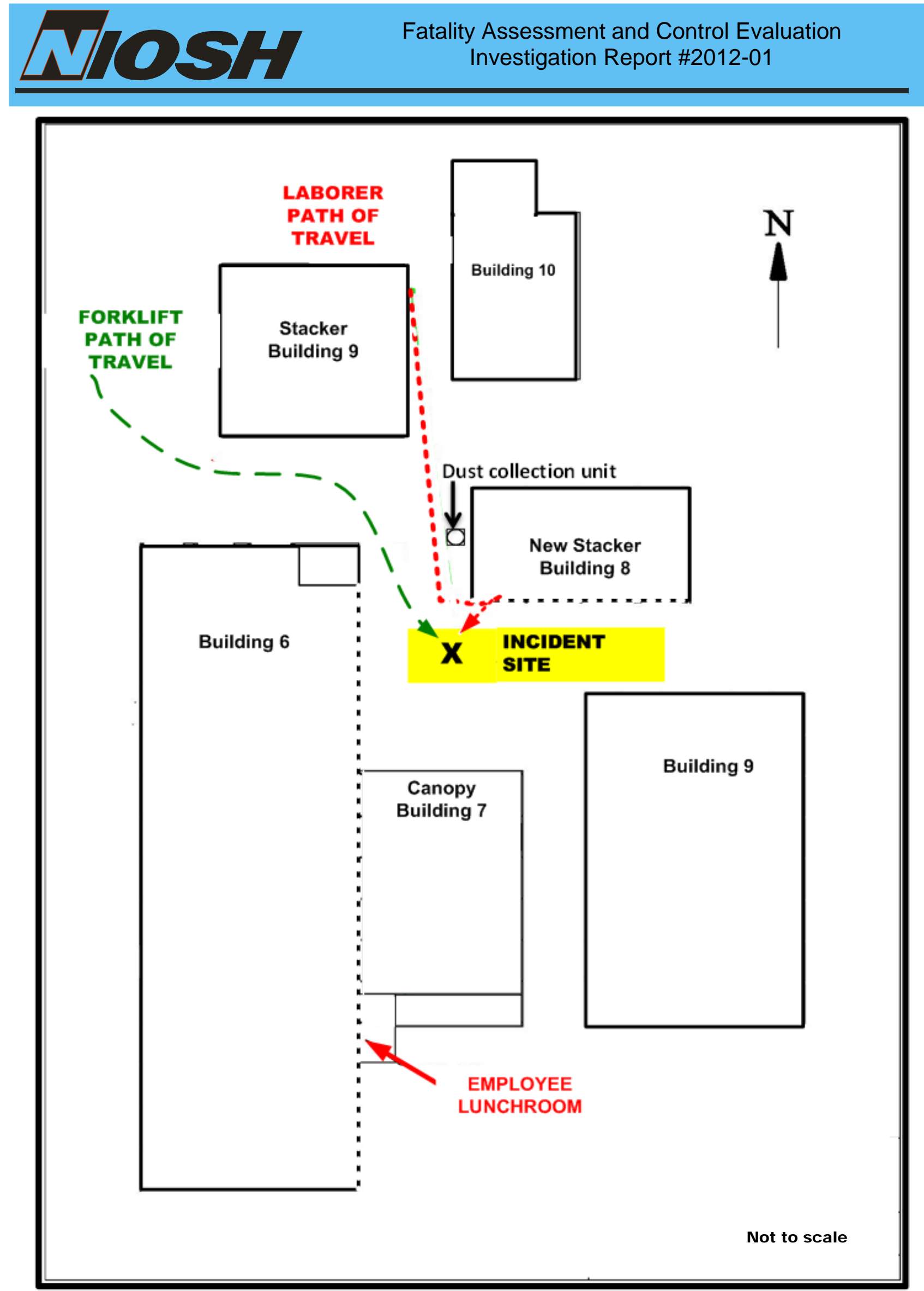

Diagram. Aerial depiction of forklift and Laborer's travel path. 
The staffing agency, through which the lumberyard laborer was hired, provided additional general safety training and coordinated additional job specific training with each individual employer. The safety training, which was provided in Spanish for the laborer, included guidance on personal protective equipment, hazard communication, housekeeping, fire prevention, machine guarding, bloodborne pathogens, lifting, and confined space entry. To assess participant comprehension, a three-page test was given in English or Spanish following the safety training.

\section{VICTIM}

The 58-year-old Hispanic male lumberyard laborer was approximately 5 feet 5 inches tall. His native country was Mexico and his first language was Spanish. He had been in the United States since 2000 and read and spoke English with some difficulty. He had worked as a lumberyard laborer for the current employer for a little over one year before the incident occurred. His duties were to unload lumber from a conveyor and then stack the lumber onto a pallet while placing spacers between the layers of lumber to facilitate the drying process. He was not wearing PPE at the time of the incident. At the time of the incident the laborer was on his way to his lunch break.

\section{INCIDENT SCENE}

The incident occurred in an open area between buildings that was approximately 35 feet across with a concrete surface (Diagram). There was an area of concrete deterioration toward the west side of the forklift travel lane. The lumberyard laborer was walking from B9 to B8, a distance of between 600 to 900 feet. He had about 200 feet to go to reach his destination, the lunchroom.

Forklift traffic was common in the area due to continual movement of lumber from the drying area to the shipping area. At times, workers and forklifts shared the same travel path with workers walking to and from buildings and assigned work areas, while the forklifts were transporting lumber from one building to another. Employees were instructed to use caution, stay alert, and walk in areas where forklifts did not travel when possible. After the fatality, the employer clearly marked the pedestrian pathways and instructed workers to stay within the marked areas.

A dust collection unit was located approximately 15 feet from where the laborer was struck (Photo 1). The unit was activated only when needed and was in operation when the incident occurred. According to NCDOL/OSH, the noise level readings taken while the system was operating registered between 85.1 and 86.9 decibels adjusted (dBA). These levels are in compliance with Occupational Safety and Health Administration (OSHA) regulations; however depending on proximity to the dust collection unit, the noise may have been loud enough to interfere with a pedestrian's ability to hear an approaching forklift. Forklifts have an average decibel level of $89.4 \mathrm{dBA}^{1}$. 

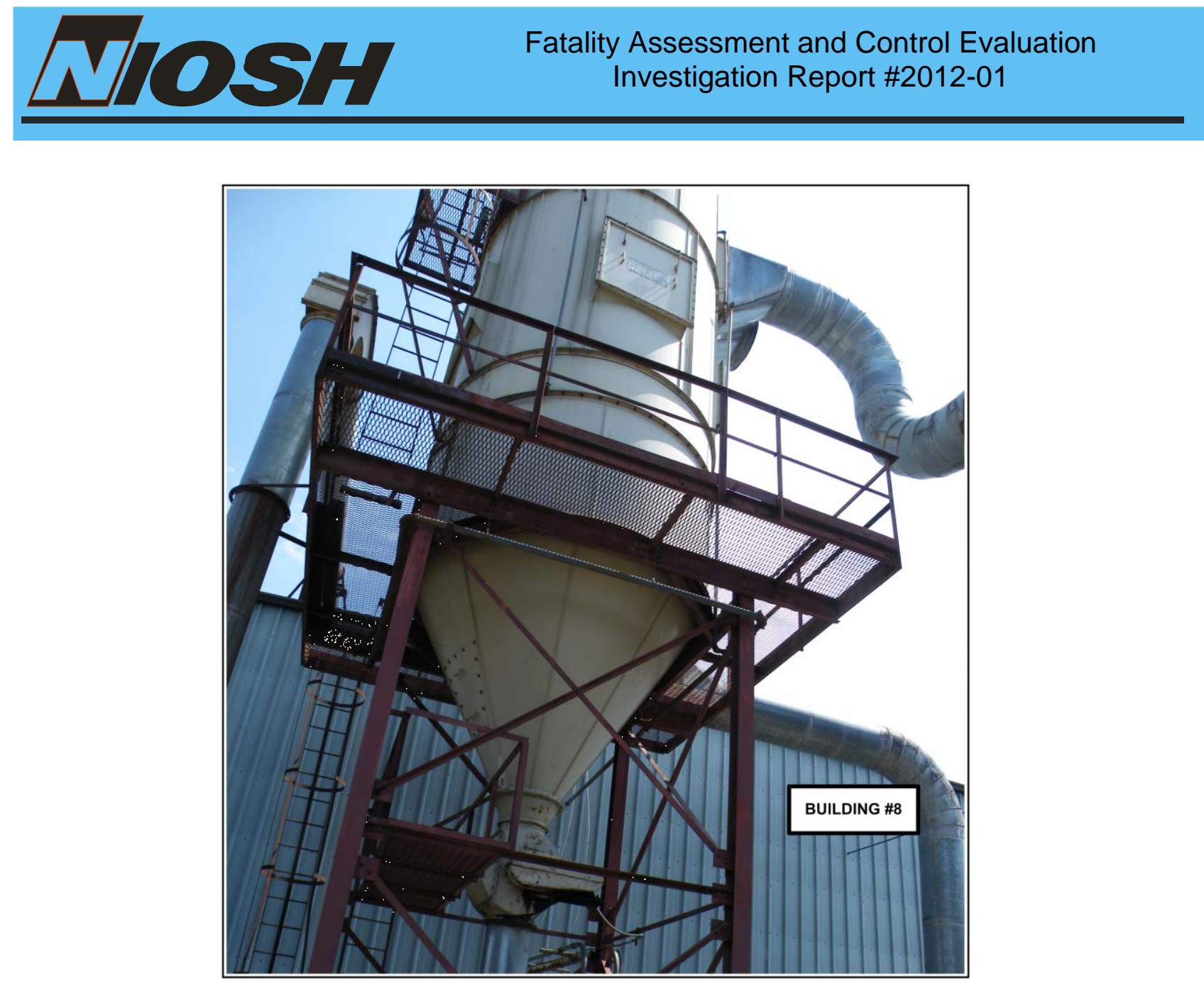

Photo 1. Dust collection unit. (Photo courtesy of NCDOL/OSH)

\section{EQUIPMENT/PERSONNEL}

The laborer was struck by a 33,000 pound capacity forklift which was manufactured in 1990 with one forward-facing driver's seat. The cab was enclosed with glass doors on each side of the driver's seat and equipped with an operational horn, back-up alarm, and flashing light affixed to the top rear of the cab enclosure. The distance from the ground to the bottom of the driver's seat was 5 feet 8 inches and the distance from the mast to the end of the stacks of wood measured 8 feet 1 inch (Photo 2).

At the time of the incident, the forklift was traveling forward at an estimated speed of one mile per hour (MPH). It was transporting two stacks of lumber measuring 7 feet, 2 inches high, 4 feet, 1 inch wide, and 12 feet 2 inches long. The forks were raised six inches off the ground, which would place the top of the load at 7 feet 8 inches (Photo 3). All powered industrial trucks at the facility receive a bi-monthly preventative maintenance inspection. The forklift involved in this incident had been last inspected on February 9, 2012.

The 63-year-old forklift operator had been with the company for 12 years. He reportedly had made 12 to 15 trips along the same route that day prior to the incident. During his time with the company, the forklift operator had not been involved in any injury-related incidents. 


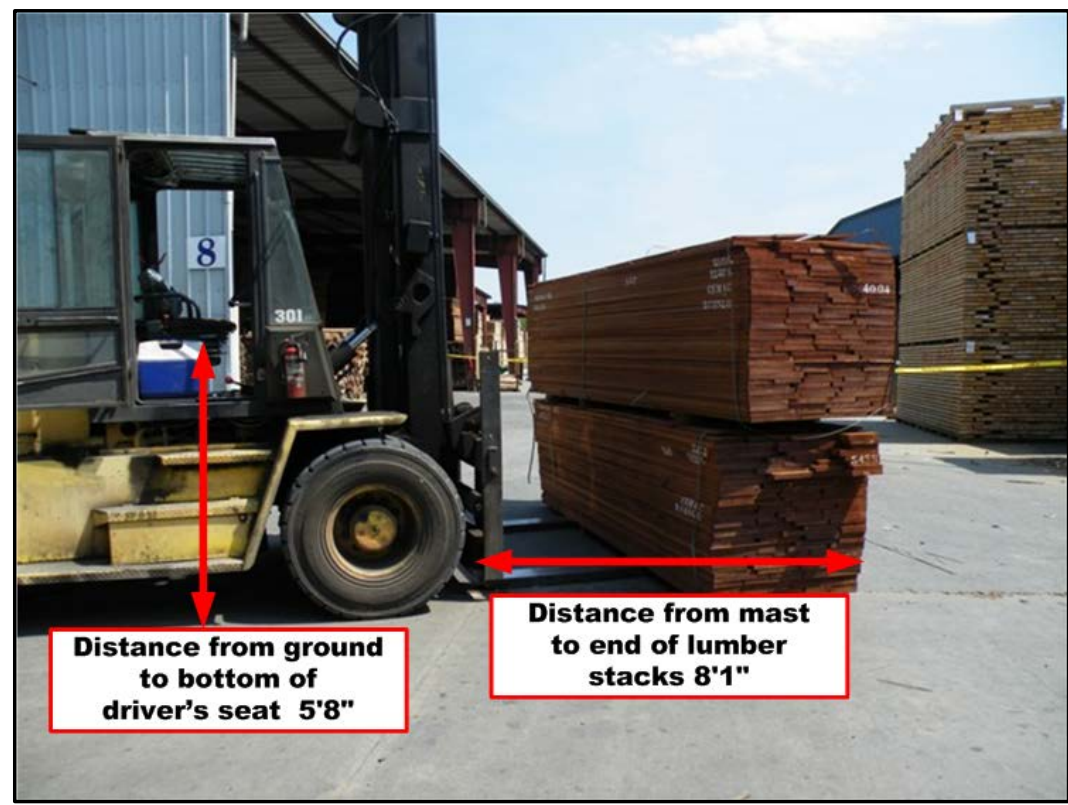

Photo 2. Photo showing a side view of the forklift and load of lumber. (Photo courtesy of NCDOL)

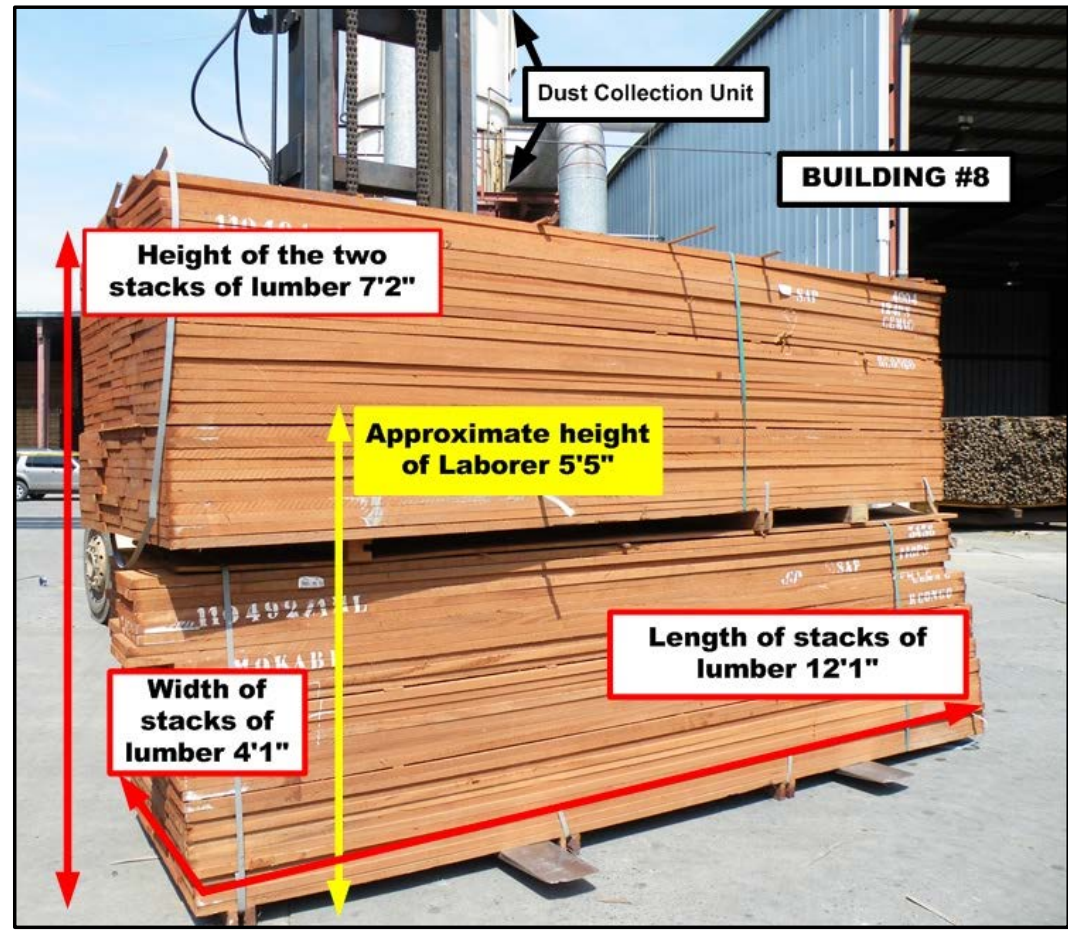

Photo 3. Area where incident occurred and pertinent measurements. (Photo courtesy of NCDOL/OSH) 


\section{WEATHER}

The incident occurred at 11:50 in the morning. At that time, the skies were clear with a temperature of approximately $70^{\circ} \mathrm{F}$ and humidity of $52 \%$. Winds were calm and there was no precipitation in the area. ${ }^{2}$ The weather is not believed to have been a factor in this incident.

\section{INVESTIGATION}

On March 30, 2012, at approximately 7:00 a.m. the lumberyard laborer began his workday at the lumberyard where he was employed through a staffing agency as a temporary lumberyard laborer. He had been assigned to two separate work areas that morning, first to B8 and later to B9 (Diagram). His duties were to place spacers between stacks of lumber to facilitate the drying process. At approximately 11:45 a.m., he stopped work to eat lunch. The employer had provided a lunch/break area for workers located in B7. It is believed that the laborer's path of travel to get to the lunch area would have taken him from B9 to B8 and then to B7 (Diagram).

There were no witnesses to the incident. However, it is believed that the laborer had left his lunch box in B8 since that was where he had begun his workday; so instead of taking a direct path from B9 where he had been working, to B7 where the lunch area was located, he would have gone first to B8 to pick up his lunch box. This would have taken him very close to the dust collection unit.

Near the area where the laborer was struck, the concrete road surface had begun to deteriorate along the west side of the forklift travel lane. It was common for operators to steer to the left to avoid the uneven road surface when they were transporting lumber from B9 to B8, which was the forklift operator's intended path of travel. This maneuver would have placed the forklift close to the dust collection unit. Therefore, the routes that the laborer and the forklift operator took would have placed both of them in proximity to the dust collection unit at the same time (Diagram). It is possible that the forklift operator could not see the laborer due the height of the load of lumber (Photo 4.) The laborer may not have seen the forklift because he was facing the opposite direction heading to B7, and may not have heard it due to the noise from the dust collection system.

The forklift operator reported that he thought he saw someone in the distance trying to get his attention, felt the forklift roll over something, and he immediately stopped. When he exited the cab, he saw the laborer lying near the left side of the forklift (as viewed from the operator's seat). He immediately radioed for help.

Emergency services personnel arrived on scene and initiated life support measures. However, attempts to resuscitate the laborer were unsuccessful and he succumbed to his injuries. He was pronounced dead at the scene by the county coroner. 



Photo 4. Photo taken from the forklift driver's seat showing obstructed forward facing view. (Photo courtesy of NCDOL/OSH)

\section{CONTRIBUTING FACTORS}

Occupational injuries and fatalities are often the result of one or more contributing factors or key events in a larger sequence of events that ultimately result in the injury or fatality. NIOSH investigators identified the following unrecognized hazards as key contributing factors in this incident:

- Forklift operator's field of vision was obstructed in the direction of travel by the load of lumber he was transporting and surrounding buildings

- Equipment and pedestrian pathways were not clearly marked or their use enforced

- Laborer's ability to hear the oncoming forklift may have been hampered by noise from the dust collection unit.

\section{CAUSE OF DEATH}

The medical examiner listed the cause of death as head and thoracic injuries. 


\section{RECOMMENDATIONS / DISCUSSION}

\section{Recommendation \#1: Employers should develop, train on, implement, and enforce safe forklift operating procedures.}

Discussion: OSHA regulations provide requirements for the safe operation of forklifts and should be incorporated into a formal safety program at worksites where they are used. Employers should establish a written program, in the language(s) and for the literacy level(s) of workers. The program should include forklift safety policies and procedures, mandatory training, personal protective equipment required for the job, and training in hazard recognition and the avoidance of unsafe conditions.

Safely operating a forklift requires preparation, anticipation of operational hazards, and careful attention in order for the operator to maintain control at all times. A formal forklift safety program should include recommended practices associated with each of the following operations:

- Pre-operation - Inspecting and maintaining the forklift before use,

- Traveling and maneuvering - Using safe operating practices to prevent accidents,

- Load handling - Identifying the hazards and recommended practices for each step in the load handling process including discussion on the individual characteristics of each type of load to be carried.

Forklift training is not only necessary so that the worker can learn how to operate the equipment, but a formal forklift training program is required by OSHA. The OSHA regulation for forklift training [29 CFR 1910.178(1)] requires operator training and periodic evaluations of operator performance. ${ }^{4}$ The standard addresses specific training requirements for forklift operation, loading, seat belts, overhead protective structures, alarms, and maintenance. At a minimum, training should include the following instructions for forklift operators:

- Do not move the forklift if you do not have a clear view of travel. OSHA forklift regulations state that "The operator is required to look toward and keep a clear view of the travel path [29 CFR 1910.178(n)(6)],"

- Slow down, stop and sound horn at intersections, corners, and wherever your vision is obstructed,

- When provided, use flashing warning lights or backup alarms when traveling in reverse,

- Use a spotter for blind spots,

- Always look in the direction of travel,

- Start, stop, travel, steer and brake smoothly,

- Signal to pedestrians to stand clear,

- Do not allow anyone to stand or pass under the load or lifting mechanism. ${ }^{4}$ 
Additionally OSHA standards specifically address that operator training should include guidance and instruction for the following issues:

- $\quad$ surface conditions,

- composition of loads,

- load manipulation,

- pedestrian traffic,

- restricted operating areas,

- hazardous locations,

- ramps and sloped surfaces,

- closed environments,

- unique or potentially hazardous environment in the workplace that could affect the safe operation of the forklift.

Refresher training should be conducted every three years. Refresher training is required if the operator is observed operating the forklift in an unsafe manner, is involved in an incident or near miss. Training must be provided in the language that is best understood by the operator, and conducted by qualified persons. It must include formal instruction, practical training, and evaluation of the operator's performance in the workplace. Retraining must be conducted if the operator is assigned to a different type of forklift. Documentation of all training should be kept on file with the company, including the operator's name, the date the training was completed, the date of the evaluation, and the name of the person who conducted the training or evaluation.

The employer in this incident had conducted forklift training in accordance with OSHA guidelines and timeframes and it was against company policy to operate a forklift with the view obstructed; company policy was to travel in reverse with the load trailing. The operator also deviated from the regular path to avoid the deteriorating concrete. Following the incident, the concrete was repaired, all workers were retrained and reminded of the company's progressive discipline policy which includes termination of employment for violations of safety policies, and supervisory personnel were charged with strict enforcement of all safety rules.

\section{Recommendation \#2: Employers should develop, train on, implement, and enforce workplace pedestrian safety procedures.}

Discussion: A universally recognized danger exists when forklifts and workers are required to perform duties in the same area. OSHA, 29 CFR 1910-176(a) requires that permanent pedestrian aisles and passageways be free from obstructions and appropriately marked where material handling equipment is used. Forklift operators should be aware of areas where there is likely to be employees walking and forklift traffic should be separated from all workers and pedestrians where possible. The greatest danger is the possibility of striking workers and causing serious injury or hitting objects and causing property damage. ${ }^{5}$ 
Procedures and physical upgrades that employers might consider implementing in workplaces where forklifts and employees must co-exist include:

- Clearly identifying employee walkways,

- Installing permanent railings, other protective barriers, or rumble strips ${ }^{\frac{5}{}}$,

- Providing adequate walking space at least on one side, if workers must use equipment aisles,

- Posting workplace speed limits,

- Installing employee walkway striping on the floor, if barriers cannot be used,

- Installing convex mirrors at blind aisle intersections,

- Posting traffic control signs.

Additionally, workers walking in or near an area where forklifts are operating should be trained how to safely interact with forklift traffic. Training should state that all workers should:

- Be aware that forklifts cannot stop suddenly. They are designed to stop slowly to minimize load damage and maintain stability,

- Stand clear of forklifts while they are in operation,

- Avoid crossing paths with forklift traffic and keep in mind that the operator's visibility may be limited due to blind spots,

- Be aware of the wide rear swing radius of the forklift,

- Use employee walkways, or stay to one side of the equipment aisle,

- Never ride on a forklift, unless authorized and the forklift is designed for riders,

- Never pass under an elevated load.

The employer had assigned walkways for employees, but rules were not always adhered to prior to this incident. Walkways were repainted and mirrors were installed at blind spots and intersections following the fatality. All employees were retrained on forklift safety and supervisory personnel were advised that strict enforcement of all safety rules was mandatory.

\section{Recommendation \#3: Employers should consider a proximity warning system (PWS) when purchasing or upgrading forklifts.}

Discussion: Forklift trucks are an essential part of many businesses. However, statistics indicate they also present a significant hazard to workers and/or pedestrians occupying the same workspace. Forklift-involved injuries can be severe or fatal because the trucks are heavy and powerful vehicles. Numerous technologies, including proximity warning systems (PWS), have been developed to address the safety concerns where forklifts and pedestrians must interact in the workplace. ${ }^{7}$

Employers may want to consider numerous factors when determining the applicability of PWS in their workplace. A safety assessment of the implementation of a PWS should be conducted 
specific to the vehicle and situation to which it is applied. PWS selection criteria for forklifts should include an active system that works in both forward and reverse. In addition, the PWS must function in blind spots and with multiple workers and machines. Any safety system should include fail-safe features to ensure that if the safety device fails, the operator is warned of the failure. Employers and workers should be reminded that there is no substitute for proper safety training. Even the best and most advanced PWS can fail to protect workers if safe work practices are ignored. All jobs should be evaluated, safe workplace protocols should be developed, and training should be provided for any situation involving the implementation of a PWS. ${ }^{7}$ In this case radio-frequency identification (RFID) or tag-based PWS technology would likely be more effective since rear mounted PWS would not have sensed the laborer.

NIOSH has published a paper on "Engineering Considerations and Selection Criteria for Proximity Warning Systems for Mining Operations." Guidance provided in this study maybe applied by managers in various industries when making decisions regarding the applicability of PWS for their specific workplace. ${ }^{8}$

\section{Recommendation \#4: Employers should ensure that contingent workers receive all required safety training and understand safe operating procedures for each job they will be performing.}

Discussion: NIOSH published an article which explored many of the issues facing contingent workers. ${ }^{9}$ The article states that, "over the past 40 years use of temporary employment has increased. These temporary workers, who make up one-third of the US workforce, do not have the same single employer relationship and are frequently referred to as "contingent workers." These contingent workers are more likely to be young, female, black or Hispanic, and to have lower incomes and fewer benefits. In addition, there is growing evidence that contingent workers are at higher risk for work-related injury, illness, and death. Possible explanations for the higher risk of work-related injury, illness, and death among contingent workers include: the outsourcing of more hazardous jobs, lack of experience and familiarity with operations in a dangerous workplace, inadequate safety training and protective equipment, and lack of access to workers compensation insurance." OSHA and NIOSH are jointly developing a fact sheet on recommended practices for the protection of temporary workers.

In order to address the safety and health of contingent workers, staffing agencies and worksite employers need to coordinate worker training on job specific hazards and ensure compliance with government mandated safety training. Under OSHA regulations, worksite employers have the primary obligation to provide workplaces free from hazards that can cause or are likely to cause death or serious physical harm. However, temporary agencies have an obligation to take reasonable steps to determine conditions at worksites and ensure contingent workers are informed of hazards and trained on methods to protect themselves.

Work contracts between temporary agencies and worksite employers should clearly outline the aspects of safety for which each is responsible. Contracts should describe who will provide both the general and the site-specific training. Tasks that require the use of personal protective equipment (PPE) must be identified. Temporary agencies and worksite employers can work 
together to assure the safety and health of all workers. A joint OSHA/NIOSH document recommends the following practices:

- Evaluate the host employer's worksite

- Train agency staff to recognize safety and health hazards

- Ensure the employer meets or exceeds the other employer's standards

- Assign occupational safety and health responsibilities and define the scope of work in the contract

- Assure both employers have and adhere to an injury and illness tracking system

- Conduct safety and health training and new project orientation

- Host employers should provide temporary workers with safety training that is identical or equivalent to that provided to the host employers' own employees performing the same or similar work

- Procedures should be in place for both reporting and obtaining treatment for on-the-job injuries and illnesses

- Staffing agencies and host employers should each have and communicate, a safety and health program to reduce the number and severity of workplace injuries and illnesses

- Conduct injury and illness prevention program assessments

- Conduct thorough investigations of injuries and illnesses

- Maintain contact with workers..$^{10}$

Point persons at both the staffing agency and the worksite should be identified and the names and contact information given to the workers so they have someone to contact when issues arise.

\section{ADDITIONAL INFORMATION}

Virtual Reality Training Program for Forklift Operators

$\underline{\text { http://ohsonline.com/articles/2013/03/11/virtual-reality-training-program.aspx?admgarea=news }}$

Temporary Agencies and Worksite Employers Share Responsibility for Keeping Temporary Workers Safe http://www.mass.gov/eohhs/docs/dph/occupational-health/temp-workers.pdf

\section{DISCLAIMER}

Mention of any company or product does not constitute endorsement by the National Institute for Occupational Safety and Health (NIOSH). In addition, citations to Web sites external to NIOSH do not constitute NIOSH endorsement of the sponsoring organizations or their programs or products. Furthermore, NIOSH is not responsible for the content of these Web sites.

\section{REFERENCES}

1. Construction Industry Noise Exposures [2004]. Department of Environmental and Occupational Health Sciences School of Public Health and Community Medicine, University of Washington Operating Engineers [http://depts.washington.edu/occnoise/content/operengIDweb.pdf ] Accessed: October 2014. 
2. Weather Underground, [http://www.wunderground.com/history/airport/KCLT/2012/3/27/MonthlyHistory.html\#c alendar] Accessed: October 2014.

3. Occupational Safety and Health Administration, Safety and Health Topics: Powered Industrial Trucks. [http://www.osha.gov/SLTC/poweredindustrialtrucks/index.html] Accessed: October 2014.

4. Occupational Safety and Health Administration: 29 CFR 1910.178, Powered Industrial Trucks.

[http://www.osha.gov/pls/oshaweb/owadisp.show_document?p_table=STANDARDS\&p_id= 9828] Accessed: October 2014.

5. Federal Highway Administration: Rumble Strips and Stripes http://safety.fhwa.dot.gov/roadway_dept/pavement/rumble_strips/ Accessed: October 2014.

6. Occupational Safety and Health Administration: 29 CFR 1901.176, Material Handling and Storage.

[http://www.osha.gov/pls/oshaweb/owadisp.show_document?p_table=STANDARDS\&p id=9824] Accessed: October 2014.

7. Occupational Health \& Safety Online [2007]. Your Forklift Safety Zone. [http://ohsonline.com/articles/2007/02/your-forklift-safety-zone.aspx] Accessed: October 2014.

8. Centers for Disease Control and Prevention [2008]. Engineering considerations and selection criteria for proximity warning systems for mining operations.

[http://www.cdc.gov/niosh/mining/content/pwsselection.html] Accessed: October 2014.

9. Centers for disease Control and Prevention, National Institute for Occupational Safety and Health [2008]. Journal of the American Medical Association in the article "Contingent Workers and Contingent Health: Risks of a Modern Economy" (JAMA. 2008; 299(4)) http://blogs.cdc.gov/niosh-science-blog/2008/02/19/contingent/ Accessed: October 2014.

10. Occupational Safety and Health Administration \& National Institute for Occupational Safety and Health [2014]. OSHA/NIOSH Recommended Practices: Protecting Temporary Workers. OSHA - 3735-2014; DHHS (NIOSH) Publication Number 2014-139 https://www.osha.gov/Publications/OSHA3735.pdf Accessed: October 2014. 


\section{Fatality Assessment and Control Evaluation}

Investigation Report \#2012-01

\section{INVESTIGATOR INFORMATION}

The investigation was conducted by Virginia Lutz, Safety and Occupational Health Specialist, and Jennifer Lincoln, Health Scientist, Fatality Investigations Team, Surveillance and Field Investigations Branch, Division of Safety Research. The report was authored by Virginia Lutz.

\section{ACKNOWLEDGEMEMENT}

The NIOSH FACE Program and the Safety and Occupational Health Specialists would like to acknowledge the Compliance Officer and staff of the North Carolina Department of Labor, Occupational Safety and Health Division, Michael Fiore, MS, Massachusetts FACE, and R. Ronald Sokol, CSP, Safety Council Texas City for providing assistance, and information for this investigation. 